\title{
DESARROLLO Y CRECIMIENTO EN LA ECONOMÍA MEXICANA: UNA PERSPECTIVA HISTÓRICA
}

\author{
Monika Meireles ${ }^{(*)}$ \\ Uiversidad Autónoma de México (DF), México. \\ "No México, a realidade é com frequência distinta das aparências, \\ sendo por vezes bem mais rica". \\ Celso Furtado, A fantasia organizada, 1985.
}

Recentemente se assiste um verdadeiro alvoroço na mídia com relação à possível perda do posto do Brasil como o protagonista econômico regional. A liderança brasileira foi posta em xeque depois de três anos de crescimento lento do PIB, dando razão à especulação de que o México seria a nova estrela em ascendência da América Latina. Segundo os analistas do The Economist, o país asteca se destacaria dos demais países latino-americanos por aspectos como: o fato de ter uma classe média consolidada, a existência de uma indústria de bens de consumo duráveis - composta por itens como televisões de tela plana ou smartphones - , produtos que têm cada vez maior presença na sua pauta de exportações e ajudam a manter as contas externas devidamente equilibradas.

Por isso, viemos comentar uma importante obra sobre a formação econômica mexicana. Trata-se do livro Desarrollo y crecimiento en la economía mexicana: una perspectiva histórica, de Juan Carlos Moreno-Brid y Jaime Ros Bosch (FCE, México, 2010); sem dúvida, trata-se de uma grande leitura, que tem o mérito de fazer a retomada crítica da história econômica do país ${ }^{(1)}$. O principal atrativo da publicação é o enfoque heterodoxo que fundamenta a análise histórica em um período que vai da época colonial até as reformas liberalizantes das últimas décadas do século XX.

A periodização da história mexicana apresentada na introdução, feita com base na interpretação de quais foram os obstáculos ao desenvolvimento e as soluções aplicadas

(*) Mestre, aluna do curso de doutorado do Programa de Posgrado de Estudios Latinoamericanos de Universidad Autónoma de México (UNAM). Professora da Faculdad de Economía de la Uiversidad Autónoma de México (UNAM). Endereço electrónico:<meireles@usp.br>. Recebidoem 17.10.2013, aceito em 04.12.2013.

(1) Os livros editados pela Fondo de Cultura Económica podem ser encontrados em São Paulo na Livraria Azteca, localizada na Rua Bartira, n. 351. 
em cada uma dessas etapas, pauta todo o livro e organiza a sua estrutura. Desta forma, seis capítulos são utilizados para descrever os grandes períodos da economia mexicana, o que procuramos resumidamente apresentar nos próximos parágrafos.

O livro avança procurando identificar "as origens do atraso" mexicano e aponta quais foram os obstáculos ao desenvolvimento que determinaram que os dois primeiros terços do século XIX fossem marcados pelo baixo crescimento econômico, o que acabaria ampliando dramaticamente a brecha entre o PIB per capita do México e de outros países, como os Estados Unidos, por exemplo.

De início, o autor analisa a economia colonial, com ênfase ao setor minerador (grande responsável pela pujança econômica da Nova Espanha), mas, também, de um importante setor de subsistência, surgido a reboque do setor minerador. Contudo, a preocupação central do capítulo é a reflexão sobre quais elementos se articularam para que mesmo depois do nascimento do Estado nacional, não se tivesse maiores estímulos ao desenvolvimento. São pontos destacados: a) a violência e instabilidade política oriundos da guerra de libertação nacional; b) o aumento dos custos da atividade mineira, dado o encarecimento de alguns insumos como o mercúrio; c) a diminuição na produção de prata e seu impacto negativo nos demais setores da economia; e d) a notável escassez de crédito.

A partir de 1877 , já no porfiriato, o país vive uma etapa fundamental na sua transição para a consolidação do capitalismo, passagem feita a partir da intervenção de um Estado fortalecido pela centralização política orquestrada pelo ditador e seus aliados. Assim, o segundo capítulo propõe, justamente, uma leitura da aceleração do crescimento econômico na época de Porfírio Díaz, não sem prudentemente destacar as especificidades do tipo de "modernização conservadora" que se experimentou durante o seu governo.

Ao analisar o impacto decorrente da Revolução Mexicana sobre a economia nacional, se tratou de desmistificar a desaceleração do crescimento como fruto da destruição da estrutura econômica pelo contexto de guerra civil. Durante a contenda (1910 a 1917), a instabilidade política prejudicou o crescimento, ou seja, apesar da capacidade produtiva física não ter sido destruída, houve desestímulo ao investimento, dado o contexto de incerteza. No entanto, outros setores foram diretamente estimulados no período, como o petroleiro e as cadeias produtivas vinculadas à militarização.

Os anos de crescimento na década de 1920 são explicados pelos seguintes fatores: a) a estabilização monetária e a retomada do padrão ouro em 1916; e b) recuperação das exportações e rearticulação do setor de manufaturas. Sem embargo, a retomada do crescimento esbarra, no período entre 1926 a 1932, com uma nova recessão desencadeada pela Grande Depressão estadunidense, que significou uma diminuição das exportações mexicanas para esse importante mercado e à política pró-cíclica de enxugar-se a base monetária implementada como resposta imediata à crise internacional.

A retomada mais sólida da economia veio com o governo de Cárdenas (1933-1940), e foi promovida por medidas como a adoção de políticas e a clara aposta governamental em promover a indústria como eixo da acumulação de capital e em endereçar a manufatura como setor dinâmico. A consolidação do Estado desenvolvimentista se deu com o 
Plano Sexenal, o fortalecimento da rede de financiamento público ao desenvolvimento, a reforma agrária e a celebrada nacionalização do petróleo.

O quinto ponto importante que o livro discute diz respeito ao momento auge da estratégia de desenvolvimento baseado na industrialização e dirigido pelo Estado, a "época dourada" que abarca o período de 1940 a 1970, cujo brilho é parcialmente explicado pelas políticas de protecionismo relativo aplicadas, tendo como destaque aquelas vinculadas com práticas comerciais discriminatórias, como importações seletivas autorizadas por de permissões, discriminação tarifária aos produtos importados, cotas de conteúdo nacional mínimas e subsídios via preços controlados do setor mineiro e petroleiro.

O esplendor da fase dourada se esmaeceu rápido. Esta etapa chegou a seu fim quando os desequilíbrios típicos de uma industrialização periférica e dependente passou à dominância: o milagre das altas taxas de crescimento esbarraram com o aumento da desigualdade na distribuição da renda e dos níveis de pobreza, a paralisia da produtividade no campo, o descuido com o potencial exportador da economia, a tão somente parcial internalização da produção de bens de capital, a manutenção do protecionismo tarifário por muito tempo e uma reforma fiscal falida. Em que pese este fato, o fortalecimento do mercado interno possibilitou a consolidação do setor industrial e a diversificação da estrutura produtiva.

No entanto, na sequência, se iniciam duas crises econômicas de grandes proporções: a de 1976 e a de 1982. No que toca a crise de 1982, ela foi inauguradora daquilo que em toda América Latina ficou conhecido como "a crise da dívida", cujos resultados, em termos de hegemonia do pensamento ortodoxo, são sentidos até hoje.

A partir de 1977, já na presidência de José López Portillo (1977-1982), a economia nacional teve como grande impulso a descoberta de novas reservas petroleiras num bom momento de preço ascendente do petróleo, porém, sofreu com os sintomas da "doença holandesa" na sua variação tropical: valorização cambiária, perda de competitividade das exportações não petroleiras e vívidos sinais de desindustrialização precoce. Esses aspectos foram agravados pelo massivo endividamento externo, já que a bonança do petróleo fez com que México passasse a ser um dos clientes favoritos dos bancos internacionais. Para o ano de 1981, a eminente e preocupante fragilidade financeira se fazia notar, já que era notória que a estrutura da dívida externa cada vez mais era de curto prazo, que existiu uma série episódios de fuga de capitais somados com um pobre desempenho da balança comercial não petroleira.

Às medidas de ajuste tomadas à raiz da crise de 1982, seguiu muitas outras de caráter ortodoxo, implantadas nos anos 1990, são o tema central do sexto capítulo do livro. Se na gestão da crise de 1982 por parte governo de Lopez Portillo foram tomadas medidas de natureza heterodoxa como a implementação do controle de câmbios, restrições totais às importações e a nacionalização bancária, quando assumiu Miguel de la Madrid (1983-1988), os ajustes passaram a ser ortodoxos — à exceção do Pacto de Solidariedade Econômica, programa de estabilização heterodoxo adotado em 1987.

A transformação radical da estratégia de desenvolvimento do país, abandonando a anterior de industrialização induzida pelo Estado, foi inaugurada com especial rapidez e 
baseada em eixos específicos para as reformas. O primeiro eixo foi a profunda revisão da política comercial, que começou em 1984 com uma moderada liberalização do regime de importações, passando pela adesão do país ao General Agreementon Tariffs and Trade (GATT) e culminando com a efetivação do North American Free Trade Agreement (NAFTA) em 1994. Acompanhada desta, houve a diluição prematura da política industrial, iniciada no mandato de Carlos Salinas de Gortari (1988-1994), no qual se eliminou uma série de subsídios ao setor manufatureiro, e depois com a criação de apoios específicos para a maquiladora, com especial destaque para a redução das tarifas sobre os insumos importados por essa indústria promovida pelo governo de Vicente Fox (2000-2006). O terceiro eixo das reformas repousou sobre a liberalização do investimento estrangeiro e a abertura dos mercados financeiros locais.

Já em 1989 se relativizou a regra geral do limite máximo de 49\% de participação estrangeira na propriedade das empresas que vigorava desde 1973, com exceção de setores estratégicos que seguiram como exclusividade do Estado (petróleo, petroquímica básica, energia, telégrafos e correios). A privatização de empresas públicas foi outro dos pilares da mudança em curso, sendo realizada em duas etapas: primeiramente, as empresas estatais de pouco protagonismo e, posteriormente, as empresas de grande significação para o desenvolvimento mexicano (salvo até recentemente o caso da PEMEX).

Os autores também comentam a reforma no campo, tanto na estrutura de propriedade como na revisão das políticas agrícolas. Lembremos que a propriedade comunal o ejido — foi um dos resultados da Revolução Mexicana, e estava protegida pelo artigo 27 da constituição, desde 1917 até 1992, ano que foi permitida a comercialização de terras ejidatarias. Finalmente, se pode indicar as mudanças no marco regulatório da competitividade como sexto eixo das reformas, com destaque para a criação da Comissão Federal de Competitividade (CFC), em 1992, agência pública cuja tarefa seria pesquisar e sancionar práticas monopólicas.

Os últimos capítulos são dedicados ao debate da situação atual. No sétimo capítulo, a análise se centra na avaliação das reformas neoliberais no sentido de comparar a promessa do discurso oficial — defensor de um novo balanço entre Estado e mercado na economia a partir de maiores investimentos privados, melhor eficiência produtiva, e crescentes ganhos de produtividade - com os resultados realmente obtidos. Ao avaliar o novo modelo, se destacam tanto aspectos positivos como negativos. A lista dos efeitos negativos é ampla: a) o investimento privado aumentou sua participação no investimento total porque o investimento público despencou; b) essa mudança na composição do investimento não assegurou um aumento da produtividade; c) a privatização do setor bancário veio acompanhada de um intenso processo de desnacionalização ${ }^{(2)}$; e d) vários dos setores privatizados se converteram em oligopólios privados, na contramão do argumento de que com a venda das empresas públicas se geraria um ambiente mais propício à criação de mercados competitivos.

(2) Um importante trabalho que trata da reforma do sistema bancário mexicano, bem como de outras questões relevantes da crise mexicana de 1994, é o livro de Alícia Girón e Noemi Levy titulado México: ¡Los bancos que perdimos! De la desregulación a la extranjerización del sistema financiero. IIEC, Instituto de Investigaciones Económicas. Facultad de Economía, UNAM, Universidad Nacional Autónoma de México, 2005. O trabalho está disponível em: <http://biblioteca. clacso.edu.ar/ar/libros/mexico/iiec/losbancos.pdf>. 
A rápida e profunda abertura comercial, catapultada pelo NAFTA, teve como resultado uma nova configuração da dinâmica econômica, na qual as exportações de manufaturas oriundas da maquilla aumentaram de maneira importante - assim como a importação dos seus insumos - e respondem cada vez mais por parte substancial do crescimento do PIB. Acompanhada pelos efeitos imediatos da liberalização financeira que trouxe o aumento massivo da entrada de capitais especulativos, o redirecionamento do crédito para o consumo e o aumento da fragilidade e exposição do setor bancário. Esse foi o contexto da crise vivida pelo país em 1994, a pior desde a grande crise de 1929 e, onde depois de uma etapa de abundância, se seguiu uma incisiva restrição do acesso ao crédito, prejudicando o investimento produtivo e reforçando sua estrutura dual do setor produtivo: as grandes empresas vinculadas ao comércio exterior tiveram canais favoráveis de financiamento e as pequenas e medias empresas, que são as maiores geradoras de emprego, se encontram com numa constante secura creditícia.

No que concerne às finanças públicas, o Estado mexicano passou a ter uma baixíssima carga tributária. Em 2000, ela correpondia a 11\% do PIB; em 2012, foi de 16\%. Estes são valores pífios e cuja dinâmica do erário é pró-cíclica: nos períodos de auge das exportações petroleiras se aumenta o gasto fiscal e nos momentos de recessão o cinto aperta.

Como alcançar a reativação da economia e promover uma política efetiva de superação da pobreza e de maior equidade da distribuição da renda é o argumento central do nono capítulo. Para explicar porque a convergência com os sócios do norte não se deu, se argumenta que as raízes do lento crescimento mexicano nas décadas neoliberais a partir de quatro elementos: a) o papel do comércio exterior, no qual se destaca que existiu um rápido crescimento das exportações, mas essa foi incapaz de dinamizar os demais setores produtivos nacionais; b) a estagnação e retrocesso da produtividade, explicado em parte pelo débil comportamento da produtividade total dos fatores, pelo aumento massivo do subemprego no setor terciário da economia, aguda diminuição do trabalho assalariado no total da força de trabalho e recrudescimento do tamanho do setor informal; c) o comportamento da acumulação de capital humano; e d) o declínio do investimento em capital fixo, puxado pelo frustrante comportamento do investimento público seguido do errático andar do investimento privado.

Nas suas conclusões, além de retomar as principais barreiras que em cada período histórico analisado dificultaram o desenvolvimento do país, os autores tocam num ponto nevrálgico, tanto para a teoria como para uma renovação criativa do leque de políticas econômicas de matriz heterodoxa: o adequado balanceamento entre mercado e Estado que suportaria a construção de uma estratégia de desenvolvimento mais exitosa. Desde logo, para desespero dos defensores incondicionais da supremacia absoluta do mercado, fica claro qual é o fiel da balança para Moreno-Brid e Ros: "a solução dos novos obstáculos pode requisitar mais e melhor, em lugar de menos, participação do Estado na economia." (MORENO-BRID; BOSCH, 2010, p. 340.)

A oportunidade de revisitar o livro resenhado é, em definitivo, uma leitura prazerosamente obrigatória para aqueles que queiram conhecer mais da história econômica e do contexto atual desse nosso querido vizinho com o qual não temos fronteira. 


\section{BIBLIOGRAFIA}

MORENO-BRID, Juan Carlos; BOSCH, Jaime Ros. Desarrollo y crecimiento en la economía Mexicana: una perspectiva histórica. México: Fondo de Cultura Económica, 2010. 